\title{
A TELEVISIÓN LOCAL NA ESTRUTURA AUDIOVISUAL DE GALICIA. O IMPACTO TECNOLÓXICO NO VALOR DE IDENTIDADE. ESTIGMAS, CONDICIONAMENTOS E RETOS DO MEDIO TELEVISIVO LOCAL
}

\author{
Ana Isabel Rodríguez Vázquez \\ Facultade de Ciencias da Comunicación da USC
}

Iniciando o século XxI, a estrutura audiovisual de Galicia estase a ver claramente reforzada a través dunha serie de accións compartidas polos poderes públicos e as empresas nun intento decidido de potenciar a industria da produción e comercialización/difusión/distribución de produtos cos que explotar a identidade sociocultural do país, tanto dentro como fóra das nosas fronteiras.

Definido pola Lei 6/1999, do 1 do setembro, o sector audiovisual galego queda circunscrito ao conxunto de actividades que utilizan como canle de desenvolvemento e transmisión da mensaxe os medios auditivos e visuais (artigo 1). Estrutúrase, pois, arredor de empresas ${ }^{1}$ produtoras (de cine, vídeo, televisión, multimedia e servizos), distribuidoras (videográficas e cinematográficas), exhibidoras (salas de cine) e emisoras (autonómica, operadora de cable e locais), que forman parte dunha serie de novos instrumentos creados ao abeiro das políticas de impulso dun sector cualificado de «estratéxico e prioritario» polo artigo 5 do mencionado texto legal, que lle confire unha importancia cultural, social e económica como instrumento para a expresión do dereito á promoción e divulgación da cultura, da historia e da lingua como elementos de autoidentificación. Declaración que leva un compromiso activo coa promoción e apoio a iniciativas educativas, profesionais e industriais, nos ámbitos público e privado, e nun marco de evidente impulso á conservación e difusión dos valores de identidade de Galicia mediante os produtos creados polas industrias audiovisuais, das que non se poden desprender as televisións

1. Audiovisual galego 2003. Consellaría de Cultura, Comunicación Social e Turismo da Xunta de Galicia. P. 15. 
locais, xa integradas nos órganos concibidos para o entendemento administración-sector, como o Consorcio -ao que se vincula a Galicia Film Commission- e o Consello audiovisuais; así como o Clúster promovido desde a iniciativa empresarial co fin de crear sinerxías no sector e con outros afíns.

Moitos anos transcorreron desde as primeiras manifestacións de cine galego e o primeiro sinal televisivo -por non mencionar o caso radiofónico ao quedar tamén á marxe das accións públicas de reanimación do sector-, ata a confección do tecido actual que, excluíndo as exhibidoras e distribuidoras, está integrado por arredor dun centenar de produtoras, unha emisora autonómica de televisión, unha operadora de cable e unha trintena de televisións locais.

Partindo de iniciativas directamente públicas no ámbito do municipio, de impulsos sociais a través de colectivos de veciños con especial peso da mocidade, de accións educativas (cursos de formación en imaxe e son, escolas...) ou de experiencias comerciais a través de empresarios locais -nalgúns casos xa relacionados co audiovisual a través de produtoras-, as televisións locais en Galicia levan xa 22 anos integrando un sector que, no caso específico da televisión, xermina no país en 1971, coa apertura de TVE-Galicia como primeiro centro produtor de contidos televisivos de Galicia e en galego. Previas foron a recepción do primeiro sinal de TVE en 1961, a primeira emisión desde Santiago de Compostela das festas do Apóstolo o 24 e 25 de xullo de 1962 ou a captación do sinal da entón Segunda Cadea (hoxe La 2) en 1967. Un proceso de aproximación na recepción e produción de contidos televisivos galegos que, se ben comeza co centro produtor de TVE en Galicia -que durante máis dunha década sustenta en solitario o peso da emisión e arredor do que xorden as primeiras iniciativas de produción allea a través de pioneiras produtoras independentes de contidos televisivos-, ten en 1985 o seu principal punto de inflexión coa rexionalización televisiva que supón a apertura da TVG, que, ademais de ampliar as posibilidades de emisión de contidos galegos, amplifica tamén o sector audiovisual, xa que baixo o 
amparo da canle autonómica xorden empresas produtoras que teñen como principal obxectivo «axudar» a completar a grella da TVG, trasladando a Galicia un fenómeno que xa se dá no resto de España e que se incrementa sen freo coa aparición das televisións privadas: a externalización da produción para televisión.

\section{A TELEVISIÓN LOCAL NA ESTRUTURA AUDIOVISUAL DE GALICIA}

Pero entre a fase inicial da rexionalización televisiva que se produce en arredor da TVE-Galicia e a consolidación do fenómeno coa posta en marcha da TVG prodúcese o nacemento dun novo medio que supón un paso adiante e colofón do proceso de aproximación da televisión ao cidadán: a televisión local.

Localizada a primeira experiencia na ría de Pontevedra en xullo de 1982 (só un ano despois da aparición da que se considera primeira televisión local de España: Tele Cardedeu), durante estes vinte anos de historia do medio foron moitas as iniciativas que xurdiron no territorio galego. Algunhas delas conseguiron manterse no tempo, outros proxectos non chegaron a nacer e houbo experiencias que logo dun tempo de actividade desapareceron.

O primeiro mapa de televisións locais correspondente a finais do século xx daba conta de iniciativas xa esmorecidas como Tele Groucho (1985), Narón Tv (1988), Monterroso Tv (1988), Canal 27 de Monforte (1991), Morraso Tv-Moaña (1991), Verín Tv (1991), Televisión Lugo (1994), RTTL (1995), Tele Boqueixón (1995), RTC (1995) e TV Melide (1997), entre outras; ás que non puideron sumarse outros proxectos que como as televisións municipais de Vigo ou de Lalín (1990 e 1994, respectivamente), a TV Chairega (1994), Mondoñedo Tv (1995) ou o Canal 31 de Monforte de Lemos (1996) se anunciaron pero nunca chegaron a poñerse en funcionamento.

Xa no século XXI, no mapa que se pode considerar actual (con todas as dificultades de cuantificación e localización que se producen á hora de determinar as emisoras dada a inestabilidade permanente do sector), localízanse un total de 34 emisoras. A 
maior concentración de emisoras de proximidade de Galicia atópase na provincia de Pontevedra, con 14 televisións (Canal 41-Fátima, Canal 50 A Guarda, Canal Deza, Galivisión Marín, Tele Baixo Miño, TV Luso-Galaica, Localia Tv Pontevedra, Localia Tv Vigo, RTV Tui, TVM Cangas, A Estrada Tv, Ponteareas Tv, TeleSalnés e Tele Vigo-La 7); seguida da Coruña con 11 (TV Ames, TV As Mariñas-Oleiros, Localia Tv Coruña, Localia Tv Ferrol, Localia Tv Santiago, RTV As Pontes, RTV Cerceda, TeleCoruña, TV Ferrol-Canal 31, TV Teo e Tv Tambre); Ourense con 5 (Cablevisión O Carballiño, Ourense Tv Benposta, Ribeira Sacra Tv, Tele Miño e Tv Arnoia); e Lugo con só 4 emisoras (Localia Telelugo, RTVM Quiroga, Televinte Chantada e TV7 Sur).

Logo de vinte anos de andadura, as televisións locais confírmanse como o último elo da estrutura audiovisual galega, que, a pesar da tendencia á concentración, mantén con estes medios a proxección descentralizadora da televisión que as novas tecnoloxías se encargarán de situar no seu xusto termo, facilitando ferramentas de grande accesibilidade que, manexadas desde a correcta perspectiva dos medios de proximidade e aparcadas as dificultades derivadas da regulación lexislativa arredor do dixital, fomentarán a democratización da produción e recepción televisivas, incentivando as esencias primixenias das televisións locais, que son coincidentes coas aplicacións e os servizos de valor engadido que ofrecen as novidades tecnolóxicas: multiciplicidade, converxencia e interactividade (participación).

\section{O IMPACTO TECNOLÓXICO NO VALOR DE IDENTIDADE}

As novas tecnoloxías están a ser asumidas polas televisións locais desde unha dobre vertente:

- Como novo elemento de inestabilidade desde o punto de vista legal e de reconversión á TDT: aínda que aliviadas coa moratoria do swich-off ata 2008 e admitido polo Goberno central un novo marco de diálogo que axude a resolver as numerosas alegacións presentadas ao mapa de demarcacións fixado polo Plan Nacional que as TVL consideran lesivo para os seus intereses e para o mantemento do valor de identidade das distintas áreas de influencia das emisoras operativas e futuras, as televisións locais 
conviven, unha vez máis, cun elemento xerador dunha permanente inestabilidade que impide o normal desenvolvemento e o asentamento definitivo do sector.

- Como porta de futuro para a recuperación do valor incontestable das emisoras de proximidade: a converxencia tecnolóxica (televisión dixital/televisión-internet/sociedade da información) permite pensar en aplicacións directas das novas tecnoloxías na potenciación de fórmulas de difusión combinadas de emisión en tempo real -retransmisión de eventos- con programas e servizos de acceso en VOD, procurando fuxir das ataduras temporais que impoñen as grellas e ofrecendo novas formas de difusión nun modelo próximo á «televisión á carta» tanto desde o punto de vista da accesibilidade (consumo personalizado de espazos), como de contidos (temática específicamente local); e todo iso combinado coas posibilidades de participación directa dos cidadáns como produtores (fontes, protagonistas, creadores de programas...) e usuarios/consumidores nunha sociedade globalizada tamén debido ás aplicacións das novas tecnoloxías de comunicación.

Vinculado a esta segunda vertente de impacto tecnolóxico como elemento positivo na consolidación do valor de identidade cómpre destacar o proxecto coñecido como Vila Dixital (enmarcado no programa Cidades Dixitais en Galicia promovido desde o Goberno central), no que participan os concellos de Vilalba e As Pontes. Unha das primeiras iniciativas deste segundo municipio pasa pola dixitalización dos medios de comunicación municipais: perséguese integrar radio, televisión e internet nun único medio que pasa a denominarse RTVi-As Pontes, capaz de ofrecer contidos multimedia e de xestionar a información da vila en distintos soportes dixitais. Iniciativa que se complementa coa elaboración de información local -especialmente institucional e de servizo público-, así como coa creación dunha rede cidadá que inclúe puntos de acceso gratuíto a internet de alta capacidade en todas as parroquias e formación dirixida aos veciños para o manexo das novas tecnoloxías e, polo tanto, a democratización nos estados de recepción dos medios capaces de soster e fomentar a identidade local. Concibido como un portal cidadán de servizos, información e apli- 
cacións que fomenten a participación directa dos veciños e a súa alfabetización dixital, RTVi-As Pontes convértese nun referente do que pode implicar a «revolución» tecnolóxica na necesaria redefinición das televisións locais, que obrigatoriamente deben recuperar o modelo de arranque fronte á tendencia ás concentracións que vulnera a esencia primixenia destes medios e levar a concibir popularmente como televisións locais unha serie de emisoras que, radicadas nunha localidade, convértense en postes difusores dun sinal supralocal que ocupa a oferta maioritaria e provoca unha preocupante e progresiva redución dos niveis de produción propia das televisións vinculadas que deixan de considerarse emisoras locais para converterse en estacións difusoras e produtoras de contidos para unha cadea que elimina dos seus obxectivos de partida a potenciación dos elementos de identidade dunha zona (costumes e tradicións, cultura, eventos, etc.).

Especificidades arredor da identidade sociocultural que recobran un valor e significado especiais nunha estrutura de comunicación globalizada tendente á multiplicidade de canles co conseguinte efecto de fragmentación das audiencias e unha maior democratización no acceso ao consumo de contidos e servizos polos usuarios. Un auténtico servizo público de comunicación e información arredor de determinadas identidades locais que potencia a coñecida formulación de McLuhan, que concibe unha gran sociedade globalizada - unha gran aldea global- integrada por pequenas aldeas locais que procuran manter unha identidade de seu. Nun contexto de fragmentación e multiplicidade de canles, pero de globalidade nas mensaxes e nos formatos, cobran especial significado os argumentos de xustificación dos medios locais como interesantes e necesarias alternativas para reforzar o valor económico social e cultural dunha localidade. Un ítem de identidade que medios escritos de proximidade teñen recoñecido e aceptado como principal razón de existencia e valor engadido de mercado e que foi trasladado a outros medios audiovisuais con desigual fortuna. No caso das televisións locais, forma parte da súa filosofía de arranque que nalgúns casos se conserva e potencia no tempo, pero que tamén se 
ve ameazada pola tendencia ás concentracións arredor dunha cabeceira de produción supralocal promovida por grandes grupos mediáticos que ven nas emisoras de pequena escala ou proximidade un novo nivel de explotación comercial de contidos e publicidade, á marxe dos postulados iniciais que verdadeiramente sustentan a razón de ser destes medios e que se ven reforzados nalgúns aspectos polas novas tecnoloxías.

\section{RETOS DO MEDIO TELEVISIVO LOCAL}

O inicio do século Xxi supón para as televisións de proximidade un novo compás de espera arredor dunha serie de incertezas de carácter tecnolóxico, pero tamén de definición. Atendendo ás reflexións de teóricos que, como Alvin Toffler, apostan porque a civilización da Era Multimedia ou da «Terceira Ola» redefinirá os «media» dando cabida a medios interactivos e desmasificados que permitan o equilibrio entre localismo e cosmopolitismo como unha necesidade fundamental na representación nos medios dunha comunidade que precisa crear e manter a súa identidade e as ligazóns con outras comunidades, entendemos que se debe redefinir o actual panorama arredor das emisoras de pequena escala, buscando o lugar que corresponda para as emisoras que participan das concentracións creando novas redes de cobertura nacional -e que non se poden considerar en ningún dos casos televisións locais-, e para aquelas televisións de proximidade que, asumindo os verdadeiros intereses mediáticos da comunidade, se manteñen como auténticos referentes de medios locais que atopan na sociedade global un lugar privilexiado no mercado que, segundo o pensamento do profesor Jesús Timoteo Álvarez², coa transformación das sociedades en «sociedades da información», se gañará a través de pautas como a diversificación, a interactividade e a tendencia ao local. Igual aposta por un sector audiovisual local de referencia José Martí cando di:

2. Cita recollida por Macía Mercade, J.: La comunicología regional dinamizadora de la estructura comunicacional española. Universidade Complutense. Madrid. 1992. 
No hay duda de que las estrategias programáticas de una emisora se inscriben básicamente en un marco geográfico específico y también en un contexto productivo concreto (...) El escenario de futuro de las famosas autopistas de la comunicación se dibuja cada vez más con tintes locales, con redes de distribución y consumo específicas y de ámbito territorial reducido; pero no sólo estamos asistiendo a un cambio a nivel de los aspectos de comunicación, ya que lo social, lo cultural e inclusive lo político parece reencontrarse de manera prioritaria en el escenario local. Frente a lo global y lo planetario, lo local evoca, como dice Balandier, aquello que se puede ver, tocar, aprehender y por tanto ser comprendido; localmente se hace el aprendizaje social y se construye la personalidad social; localmente se definen los retos de la vida cotidiana, localmente por último se presentan las redes concretas vinculadas al devenir de la vida cotidiana ${ }^{3}$.

Apoiando esta teoría da consolidación do mercado local como tendencia atopamos tamén as reflexións de John Sinclair, Elizabeth Jacka e Stuart Cunningham ${ }^{4}$, que recollen no seu estudo conxunto as teses de Joe Straubhaar ao presentar que as audiencias buscarán, en primeiro lugar, o pracer do recoñecemento da súa propia cultura na súa selección dos programas, preferindo, xeralmente, a programación máis próxima á súa propia cultura e provocando a apertura de novos mercados xeolingüísticos localistas e transcontinentais. Consideran, pois, necesaria a aplicación da ciencia xeolóxica que permite ver os niveis mundial, nacional, rexional e local como capas de distribución de programas de televisión e outros bens culturais, cunha excepción: trátase de capas non sedimentadas, senón superpostas e entrecruzadas. Equilibrio entre o global e o local que o profesor Ángel Benito sitúa na ampla distribución do que denomina «medios secundarios de comunica-

3. Martí, J.: «La programación local en radio. Formatos y tendencias». Relatorio presentado no seminario da UIMP celebrado en Cuenca. 1994. Publicada no suplemento Telos «El horizonte de la Sociedad de la Información», n. ${ }^{\circ}$ 41. P. 48-55.

4. Sinclair, J.; Jacka, E. e Cunningham, S.: «Mercados regionales de televisión en la era de los satélites. Una visión periférica de la comunicación global», Telos. Cuadernos de Comunicación, Tecnología y Sociedad, n. ${ }^{\circ}$ 47. Setembro-novembro. 1996. P. 39-45. 
ción: la prensa, radio y televisión local, comarcal y provincial (o regional) $\aleph^{5}$. Unha rede de actividades comunicativas próximas que, segundo recolle tamén o «Plan a Medio Plazo» da Unesco, converteranse no obrigado contrapeso da imparable influencia dos sistemas de comunicación globalizadores, polo que se supón que a

creación de medios de comunicación descentralizados puede favorecer una participación mayor, principalmente por lo que respecta a comunicación y desarrollos rurales, y permitir que públicos desfavorecidos reciban informaciones más abundantes, procedentes de fuentes más diversificadas y que correspondan mejor a sus necesidades, puede ofrecerles también la posibilidad de no tener que limitarse a ser receptores pasivos, sino que puedan dar a conocer las propias preocupaciones y opiniones.

Entre as minorías con personalidade e poder crecentes xorden con perfís singulares as comunicacións de ámbito abarcable, desde as locais ás rexionais, debendo existir un conduto polo que as necesidades, os intereses e as realizacións dunha comunidade local poidan comunicarse verticalmente cara a arriba e horizontalmente cara a fóra (Wilbur Schramm); por iso nunha sociedade caracterizada polo anonimato e a dimensión mundial dos acontecementos emerxe unha corrente revitalizadora do particular, o privado, o local como espazo imprescindible na rede comunicativa actual (Víctor Urrutia) ${ }^{7}$.

Recuperar, nalgúns casos, e consolidar, noutros, o modelo de televisión local como medio que fomenta o interese dos cidadáns pola información máis próxima, e na que estes atopan unha fiestra aberta á localidade da referencia, centra o debate actual arredor da televisión local. A convivencia dun erróneo concepto de

5. Benito, Á.: «Las diferentes perspectivas de la comunicación». Publicado en Cuenta y Razón, n. ${ }^{\circ}$ 34. Febreiro de 1988. P. 34.

6. Schramm, W.: «Desarrollo de la comunicación y proceso de desarrollo», en Pye, L.: Evolución política y comunicación de masas. P. 58.

7. Urrutia, V.: La prensa ante el cambio de siglo. Statistical Yearbook. United Nations. Nueva York. 1977. Reproducido en Empresa y empresario de la información. P. 270-271. 
televisión local -baseado nas concentracións- fronte ao que se viña asentando e fundamentando na existencia de pequenas emisoras contrapostas arredor dun modelo público ou comercial, rural ou vilego pero que participan dos postulados de base teorizados arredor dos medios de proximidade, está a desvirtuar o xa de por sempre heteroxéneo sector das televisións locais. Sen desbotar as propostas comercial e tecnicista expostas por Mario Viché ${ }^{8}$ arredor das emisoras televisivas de proximidade, pódese retomar o modelo como punto de partida para a redefinición da televisión local do futuro: a través dos promotores da emisora xéranse unha serie de producións que se converten en auténticos expoñentes da realidade cultural local, foméntase unha canle de comunicación bidireccional entre os colectivos locais, un foro de debate dos problemas que afectan á localidade nun medio axeitado para que os cidadáns, ben individual ou colectivamente, poidan expresar a súa palabra e comunicala á poboación. Un modelo en que a animación sociocultural toma partido favorecendo o desenvolvemento de redes locais de tipo bidireccional, promovendo a produción de programas que asuman a identidade cultural e local e sexan verdadeiro foro de debate na comunidade, favorecendo tamén o acceso dos individuos e os colectivos á produción destes espazos e, en xeral, á comunicación local e facilitando a difusión da información de proximidade. Porque a TVL é un dos elementos que axudan a facer territorio, a fixar e desenvolver os seus sinais de identidade colectiva e defenden a existencia destes medios como peza fundamental, non só desde o punto de vista da identidade cultural, senón desde a perspectiva do establecemento de redes de comunicación intraterritoriais e como garantía da liberdade de expresión e comunicación da colectividade.

E neste contexto o impacto tecnolóxico ocupa un lugar preferente por canto conduce á diversificación dos produtos que van á procura dos intereses específicos das audiencias. Un público que, segundo Claude-Jean Bertrand ${ }^{9}$, orienta a súa demanda cara

8. Viché, M.: Animación, sistema de comunicación. Redes de comunicación y televisiones locales. Grup Dissabte. Valencia. 1991.

9. Domínguez, J.: «Revolución en los medios de comunicación». Boletín «Aceprensa», n. ${ }^{\circ} 12$. Servicio 44/86, 2/4/1986. Este artigo recolle as palabras do profesor Claude-Jean 
ao local, o humano e a diversión (...). Como membros dunha sociedade masificada, de consumo, os cidadáns experimentan o impulso de pertencer a pequenas comunidades e de participar nun propio destino; de aí a tendencia xeral á descentralización.

Novas tecnoloxías que son, polo tanto, compatibles e mesmo axudan a referendar as teses dos medios necesarios para preservar os valores de identidade. As liñas de actuación artelladas arredor dos obxectivos fundamentais recollidos no artigo $8^{\circ}$ do capítulo II, onde se dispón a promoción dun mellor coñecemento da historia, a arte, a literatura, a música, as producións culturais e, en xeral, a realidade social galega a través das producións cinematográficas e audiovisuais, ao mesmo tempo que se impulsa a produción propia e a coprodución, así como a distribución por calquera dos sistemas e das canles de difusión audiovisual, son altamente coincidentes cos criterios fundacionais que marcan a esencia das televisións locais como medios audiovisuais de proximidade.

Uns medios que, no caso galego, se ven imposibilitados para abandonar os estigmas que desde sempre condicionaron a súa evolución e se manifestan, mesmo, á hora de afrontar os novos retos. Como estigmas das televisións locais entendemos unha serie de consideracións de partida arredor destes medios considerados modestos, con escasos recursos técnicos e de profesionais, sometidos a un marco xurídico que aínda hoxe xera unha fonda inestabilidade (alegalidade - ilegalidade -adaptación tecnolóxica/administrativa), en moitos casos faltos de recoñecemento dos seus valores potenciais, con gran heteroxeneidade de modelos e propostas que dificultan os traballos comúns pola consecución duns obxectivos, con conexións aleatorias entre si, o que impide o establecemento dun asociacionismo ou colaboracionismo que fortaleza un sector de por si considerado de gran febleza. E todo iso condicionou -e condiciona- a evolución destes medios de proximidade que ven freada a súa consolidación na estrutura audiovisual galega por

Bertrand pronunciadas durante o Seminario Internacional de Innovación Xornalística celebrado na Facultade de Ciencias da Información da Universidade de Navarra. 
unha limitación de recursos económicos que ten os seus efectos máis inmediatos nos niveis de produción propia que poden asumir con escasos medios técnicos e un cadro de persoal deficitario non só desde o punto de vista cuantitativo senón tamén cualitativo en canto ao nivel de profesionalidade. Os continuos vaivéns lexislativos e os cambios tecnolóxicos («aliviados» circunstancialmente pola moratoria gobernativa que atrasa ata o 2008 a obrigatoriedade da emisión das TVL en dixital) fomentan que o sector se manteña nun estado de marxinalidade na estrutura audiovisual, o que impide deseñar modelos de televisións locais, así como estratexias de futuro que permitan afianzar a estas emisoras no tecido mediático da comunidade impulsando alianzas positivas para mellorar os niveis de calidade e o número de producións propias que conformen unha oferta verdadeiramente alternativa que permita a estas televisións converterse nun auténtico referente sociocultural que reflicta os valores identitarios da localidade.

Este é un dos principais retos que deben asumir as televisións locais nestes primeiros anos do século xxi: unha lexislación que verdadeiramente ampare o sector, que a través das tecnoloxías, a investigación, a profesionalidade e o asociacionismo procure a dignificación das televisións locais, que deben traballar por redefinir o modelo que as erixa en alternativa necesaria na localidade e no marco da estrutura audiovisual á que pertence e na que se deben establecer sinerxías a través da elaboración de políticas específicas de impulso ás emisoras de proximidade.

Falar de televisión local é facelo dunha televisión próxima a un pobo: proximidade tanto física (localización das instalacións, dos equipos emisores...) como social (as emisoras deben sintonizar cos referentes do lugar); unha proximidade, pois, das súas características (funcionamento, mercado...) e dos seus obxectivos (audiencias, contidos programáticos...). A TVL despexou o camiño cara a un novo xeito de facer comunicación estreitamente vinculado ao cidadán, ao seu ámbito de vida, á súa localidade e aos seus intereses. Confluencia na contratendencia; integración na universalización; globalización na concepción e localismo na aplica- 
ción: é a procura do equilibrio permanente nos subsistemas comunicativos estruturados e diferenciados nos medios de difusión audiovisual, pero converxentes na sociedade global aglutinadora de novos modelos baseados na "coexistencia pacífica» e nunha concepción do todo a través das partes como resumo e aplicación final das teorías que apoian a difusión da mesocomunicación no marco da megacomunicación.

Partindo da recuperación das teorías primitivas que marcaron a existencia das TVL, atópanse os valores de proximidade e participación como nucleadores da esencia orixinal proxectada sobre o produto final na relación de atracción mediática cara ao público local, e viceversa; isto é, do público cara ao medio creándose interesantes sinerxías. Son os piares sobre os que se postula a televisión de pequena escala do século xxi: un produto específico da grande aldea global desde as pequenas aldeas locais onde se priman e xustifican outras carencias evidenciadas por estas emisoras que buscan a relación directa en detrimento do criterio de calidade na oferta final: é a esencia do contido sobre o continente, o qué sobre o cómo, o nós sobre o eles, o aquí fronte ao acolá, onde se antepón a autocompracencia do público á calidade do acabado do produto. É, de certo, un reforzamento das teses de Enmanuelle Mougne, para quen a televisión local é unha realidade construída arredor de dous polos: a convivencialidade e a proximidade.

$\mathrm{Na}$ redefinición do modelo de futuro é necesario reforzar tamén -igual que se está a facer co conxunto do sector audiovisual- o valor de identidade da TVL cos seus principios fundacionais recollidos por numerosos autores e aplicados en numerosas iniciativas que, entre as graves ameazas que soportan, teñen que afrontar a relativa competencia ilegal que exercen as concentracións que vulneran as esencias máis primixenias e verdadeiras razóns de existir destes medios que, como garante de supervivencia, deben apostar por constituírse en verdadeira plataforma comunicativa democratizadora (no acceso e na recepción) e de servizo público (tanto desde unha perspectiva empresarial-comercial como de iniciativa pública -política ou comunitaria-). Constitúe, 
pois, a redefinición do modelo de TVL que verdadeiramente responde á esencia do medio un dos principais esforzos que deben asumir as televisións galegas nos albores do século xxi: buscar o seu lugar específico dentro do sector audiovisual galego, complementando o actual panorama de emisión transnacional, nacional e rexional, empregando as NT como ferramentas simplificadoras dos procesos de produción e difusión, e consolidándose como iniciativas estables que xeren interesantes bolsas de emprego continuado derivado da propia estabilidade na produción e difusión de contidos.

Retomando o punto de partida: é necesario que as TVL participen activamente das políticas públicas de incentivos ao audiovisual, creándose un plan específico de actuación entre a Administración e estas emisoras, complementario das restantes iniciativas sectoriais e que dea auténtica resposta aos estigmas e condicionamentos negativos que acompañaron de sempre a evolución das TVL dotándoas dunha vulnerabilidade permanente polo seu estado de continua inestabilidade.

Moragas destaca o feito de que existen poderosas razóns culturais para que as políticas de comunicación recoñezan e apoien a existencia das televisións nas rexións e localidades. No sistema moderno de comunicación non é posible o mantemento das identidades culturais -e das linguas- sen a existencia dos medios de comunicación correspondentes aos seus ámbitos de implantación ${ }^{10}$. Entre eles, as televisións locais, que desde hai algo máis de vinte anos forman parte indispensable da estrutura audiovisual galega.

10. Moragas, M.: «Espacio audiovisual y regiones en Europa. Política, cultura y mercado». Telos. Cuadernos de Comunicación, Tecnología y Sociedad, n. ${ }^{\circ}$ 45. Marzo-maio. 1996. P. 42-52. 